\title{
ANALISIS PREVENTIVE MAINTENANCE MESIN AM KORIN DENGAN AGE REPLACEMENT DI PT NUGRAHA INDAH CITARASA INDONESIA
}

\author{
Ali Aflah Muzakki ${ }^{1}$ \\ ${ }^{1}$ Program Studi Teknik Industri, Universitas Singaperbangsa Karawang \\ Email:ai.aflah16017@student.unsika.ac.id
}

Masuk:30-08-2020, revisi: 26-09-2021, diterima untuk diterbitkan: 06-10-2021

\begin{abstract}
ABSTRAK
Kelancaran proses produksi PT Nugraha Indah Citarasa Indonesia sering mengalami gangguan karena mesin AM Korin yang bertindak untuk proses filling sering mengalami kerusakan dan menimbulkan keperluan untuk perbaikan komponen yang sangat merugikan bagi perusahaan karena waktu yang hilang untuk produksi akibat breakdown komponen mesin tersebut sehingga menyebabkan production loss. Jadwal preventive maintenance sangat dibutuhkan untuk mencegah kerusakan di masa yang akan datang untuk mengetahui interval waktu perawatan bagi komponen mesin AM Korin sehingga dapat mengeliminasi downtime berdasarkan pemilihan dengan penghematan biaya yang paling minimal. Age Replacement merupakan penggantian pencegahan berdasarkan umur dari komponen dengan mengikuti pola distribusi tertentu. Jadi penggantian pencegahan dilakukan dengan menetapkan kembali interval waktu penggantian pencegahan berikutnya sesuai dengan interval yang telah ditentukan jika terjadi penggantian akibat kerusakan yang terjadi. Metode Age Replacement berfungsi untuk memprediksikan secara akurat kegiatan penggantian komponen mesin AM Korin yang seringkali mengalami kerusakan dengan menganalisa berdasarkan data historis kerusakan komponen tersebut serta mengetahui penekanan biaya optimal untuk setiap interval waktu penggantian komponen. Hasil dari penelitian menunjukkan bahwa salah satu selang waktu penggantian optimal yaitu selama 23 hari untuk komponen sensor dengan biaya penggantian Rp. 77. 625.000 dimana menekan biaya perawatan sebelumnya yaitu sebesar Rp. 99.900.000.
\end{abstract}

Kata Kunci: Age Replacement; Preventive Maintenance; Breakdown

\section{ABSTRACT}

The smooth production process of PT Nugraha Indah Citarasa Indonesia is often disrupted because AM Korin machines that act for filling processes often experience damage and cause the need to repair components that are very detrimental to the company because of the time lost for production due to breakdown of these engine components, causing production loss. Preventive maintenance schedule is needed to prevent damage in the future to find out the maintenance time intervals for AM Korin engine components so as to eliminate downtime based on selection with the most minimal cost savings. Age Replacement is a preventive replacement based on the age of the component by following a certain distribution pattern. So preventive replacement is carried out by re-establishing the time interval for the next preventive replacement in accordance with a predetermined interval in the event of a replacement due to the damage that occurred. The Age Replacement method serves to accurately predict AM Korin engine component replacement activities that often suffer damage by analyzing based on historical data of damage to these components as well as knowing the optimal cost emphasis for each time interval of component replacement. The results of the study showed that one of the optimal replacement intervals was 23 days for sensor components with a replacement cost of $R p$. 77. 625,000 which reduces the cost of previous treatments, which is Rp. 99,900,000.

Keywords: Age Replacement; Preventive Maintenance; Breakdown

\section{PENDAHULUAN \\ Latar Belakang}

PT. Nugraha Indah Citarasa Indonesia adalah perusahaan yang bergerak di bidang FMCG (fast moving consumer goods) yaitu pembuatan berbagai macam bumbu dapur dan produk andalannya yaitu bumbu masak racik dimana dalam pengerjaan produknya menerapkan produksi massal 
(mass production). Alur proses pengerjaan produk yang dihasilkan oleh PT. Nugraha Indah Citarasa Indonesia salah satunya adalah proses filing dari bahan baku ke dalam kemasan menggunakan mesin otomatis yang dinamakan mesin AM Korin. Dalam line filling mesin AM Korin merupakan satu - satunya mesin yang dipakai dalam proses filling serta terdapat beberapa urutan proses, sehingga apabila salah satu elemen mesin mengalami breakdown atau mengalami kerusakan dapat menyebabkan terhentinya proses filling di mesin tersebut, dan menyebabkan kerugian dari segi biaya serta waktu dalam memenuhi kelancaran produksi. Produktifitas suatu perusahaan sangat ditekankan khususnya pada kelancaran produksi. Kelancaran proses produksi mempunyai tiga unsur utama yaitu input (raw material), proses (mesin), output (finish good). Unsur tersebut terdapat berbagai macam peralatan atau mesin yang perlu dipelihara demi kelancaran proses produksi. Kelancaran produksi jika sering mengalami gangguan akibat kerusakan mesin maka sangat besar dampaknya pada kualitas produk dan hasil output yang tidak maksimal sehingga menimbulkan banyak kerugian dan memperkecil tingkat produktifitas (Fansuri et al., 2017). Di area produksi, mesin yang digunakan pada mestinya harus dalam kondisi prima. Hal ini dapat dilakukan dengan perawatan mesin secara menyeluruh dan berkala oleh pihak yang terkait data perusahaan tersebut. Kelancaran proses produksi PT Nugraha Indah Citarasa Indonesia sering terganggu karena mesin mengalami kerusakan dan kerusakan yang timbul seringkali disebabkan karena keperluan untuk perbaikan komponen yang sangat merugikan bagi perusahaan karena waktu yang hilang akibat breakdown komponen mesin tersebut yang dapat dilihat pada Tabel 1 .

Tabel 1. Data Breakdown Mesin AM Korin

Sumber:PT. Nugraha Indah Citarasa Indonesia

\begin{tabular}{lcccc}
\hline Komponen & Jumlah (Unit) & $\begin{array}{c}\text { Harga } \\
(\mathrm{Rp})\end{array}$ & Frekuensi & Total Biaya (Rp) \\
\hline Sensor & 12 & 600000 & 19 & 136800000 \\
\hline Magnetic Break & 2 & 1300000 & 16 & 41600000 \\
\hline Roller Penggerak Pisau Pemotong & 2 & 285000 & 20 & 11400000 \\
\hline Roller Penggerak Seal Horizontal & 2 & 235000 & 23 & 10810000 \\
\hline Roller Penggerak Brake & 2 & 250000 & 20 & 10000000 \\
\hline $\begin{array}{l}\text { Roller Penggerak } \\
\text { Seal Vertical }\end{array}$ & 2 & 193000 & 23 & 16878000 \\
\hline Ribbon Tape & 10 & 15000 & 11 & 960000 \\
\hline Turning Gear & 2 & 40000 & 12 & 400000 \\
\hline Spring Break & 4 & 20000 & 5 & 350000 \\
\hline Spring Gear & 2 & 17500 & 10 & 222848000 \\
\hline Total & 40 & 2955500 & 159 & 16000 \\
\hline
\end{tabular}

Berdasarkan observasi yang sudah dilakukan di PT. Nugraha Indah Citarasa Indonesia ini, perlu dilakukannya penjadwalan yang optimal untuk penggantian komponen kritis yang sering mengalami kerusakan tersebut sehingga biaya produksi dapat diminimalkan (Prawiro, 2017). Jadwal preventive maintenance dibutuhkan untuk mencegah kerusakan dengan mengetahui interval waktu perawatan yang optimal bagi peralatan untuk menghilangkan downtime (Budiyanti et al., 2015; Muhsin \& Syarafi, 2018; Praharsi et al., 2015; Ramadhan \& Sukmono, 2018; Tamara, 2014; Taufik \& Septyani, 2016). Model Age Replacement merupakan metode dari preventive maintenance yang dapat memprediksikan secara akurat kegiatan penggantian komponen suatu peralatan berdasarkan data historis kerusakan peralatan tersebut serta dapat mengeliminasi breakdown dibandingkan metode preventive maintenance lainnya (Prawiro, 
2017). Model age replacement ini lebih banyak dipakai pada industri karena adanya parameter life time komponen yang tidak dimiliki metode preventive maintenance lainnya (Purnama et al., 2015). Perawatan mesin awalnya di rencanakan sesuai dengan manual book dari mesin tersebut namun tindakan preventive yang ditunjukkan oleh manual book tersebut tidaklah akurat sehingga diperlukan penjadwalan yang akurat dengan metode Age Replacement untuk mengetahui selang waktu penggantian komponen yang akurat sesuai dengan kondisi yang ada. Kompleksnya permasalahan mengenai breakdown dan besarnya skala proses produksi yang harus di capai oleh PT. Nugraha Indah Citarasa Indonesia dalam memenuhi permintaan pasar, maka dibutuhkan penanganan menganai preventive maintenance agar target produksi dapat dicapai (Prawiro, 2017).

\section{Rumusan Masalah}

Berdasarkan latar belakang yang tertera diatas, maka permasalahan yang dapat dirumuskan adalah sebagai berikut :

Bagaimana menentukan komponen-komponen kritis pada mesin AM Korin pada line filling Racik di PT. Nugraha Indah Citarasa Indonesia?

Bagaimana menentukan interval waktu penggantian dengan model Age Replacement untuk penggantian komponen kritis pada mesin AM Korin pada line filling Racik di PT. Nugraha Indah Citarasa Indonesia?

Bagaimana menentukan penekanan biaya yang terjadi setelah tindakan pencegahan pada mesin AM Korin pada line filling Racik di PT. Nugraha Indah Citarasa Indonesia ?

\section{METODE PENELITIAN}

Penelitian ini dilakukan dengan mengumpulkan data sekunder dari seluruh komponen yang mengalami kerusakan pada mesin yang akan dianalisis pada periode 2018-2019 lalu dilakukan pengolahan data menggunakan Microsoft Excel. Hasil dari pengolahan data pada Microsoft Excel berguna untuk mengetahui klasifikasi komponen, interval waktu penggantian komponen (age replacement) dan biaya alternatif (cost of preventive alternative). Penelitian ini diharapkan dapat menghasilkan zero breakdown untuk meningkatkan produktivitas perusahaan lainnya.

\section{HASIL DAN PEMBAHASAN}

\section{Klasifikasi Komponen}

Dilihat dari Tabel 2 bahwa komponen sensor termasuk dalam kategori kelas A sehingga komponen sensor menjadi prioritas penanganan yang utama, karena jika komponen ini rusak maka mesin tidak dapat dijalankan dan menyebabkan alarm Emergency Stop berbunyi sehingga menyebabkan terganggunya proses produksi serta menyebabkan line tersebut stop produksi.

Tabel 2. Klasifikasi komponen Dengan Analisis ABC Dengan Analisis ABC Pada Mesin AM

$$
\text { Korin }
$$

Sumber: Penulis, 2020

\begin{tabular}{lccc}
\hline Komponen & Total Biaya (Rp) & Persentase nilai barang $(\%)$ & Kategori \\
\hline Sensor & 136800000 & 61.54455232 & $\mathrm{~A}$ \\
\hline Magnetic Break & 41600000 & 18.71530246 & $\mathrm{~B}$ \\
\hline Roller Penggerak Pisau Pemotong & 11400000 & 4.872277058 & $\mathrm{C}$ \\
\hline Roller Penggerak Seal Horizontal & 10810000 & 4.863279317 & $\mathrm{C}$ \\
\hline Roller Penggerak Brake & 10000000 & 4.498870783 & $\mathrm{C}$ \\
\hline
\end{tabular}




\begin{tabular}{lccc}
\hline Komponen & Total Biaya (Rp) & Persentase nilai barang (\%) & Kategori \\
\hline Roller Penggerak Seal Vertical & 8878000 & 3.994097482 & $\mathrm{C}$ \\
\hline Ribbon Tape & 1650000 & 0.742313679 & $\mathrm{C}$ \\
\hline Turning Gear & 960000 & 0.431891595 & $\mathrm{C}$ \\
\hline Spring Break & 400000 & 0.179954831 & $\mathrm{C}$ \\
\hline Spring Gear & 350000 & 0.157460477 & $\mathrm{C}$ \\
\hline Total & 222848000 & 100 & \\
\hline
\end{tabular}

\section{Interval Waktu Penggantian (Age Replacement)}

Dilihat dari Tabel 3 bahwa interval waktu penggantian jatuh pada tp ke 23 nilai tersebut dipilih berdasarkan nilai $\mathrm{C}(\mathrm{tp})$ terkecil sehingga didapat interval waktu penggantian komponen sensor dengan biaya termurah dengan hasil interval waktu penggantian setiap 23 hari sekali.

Tabel 3. Hasil Age Replacement Komponen Sensor

Sumber: Penulis, 2020

\begin{tabular}{|c|c|c|c|c|c|c|}
\hline tp & $\mathrm{R}(\mathrm{tp})$ & $\mathrm{F}(\mathrm{tp})$ & $(t p+T p) * R(t p)$ & $\mathrm{M}(\mathrm{tp})$ & & $\mathrm{C}(\mathrm{tp})$ \\
\hline 1 & 0.9999999999989 & 0.0000000000011 & 1.020833333 & $3.78002 \mathrm{E}+13$ & $\mathrm{Rp}$ & $175,887.12$ \\
\hline 2 & 0.9999999923496 & 0.0000000076504 & 2.020833318 & 5217313845 & $\mathrm{Rp}$ & $171,692.88$ \\
\hline 3 & 0.9999994056014 & 0.0000005943986 & 3.020831538 & 67151084.11 & $\mathrm{Rp}$ & $167,694.03$ \\
\hline 4 & 0.9999910429054 & 0.0000089570946 & 4.020797318 & 4456189.595 & $\mathrm{Rp}$ & $163,877.53$ \\
\hline 5 & 0.9999406469025 & 0.0000593530975 & 5.020535331 & 672492.4792 & $\mathrm{Rp}$ & $160,232.75$ \\
\hline 6 & 0.9997573645065 & 0.0002426354935 & 6.019372465 & 164504.0101 & $\mathrm{Rp}$ & $156,752.94$ \\
\hline 7 & 0.9992746292296 & 0.0007253707704 & 7.015740626 & 55026.35797 & $\mathrm{Rp}$ & $153,436.45$ \\
\hline 8 & 0.9982536579755 & 0.0017463420245 & 8.006826215 & 22856.06777 & $\mathrm{Rp}$ & $150,286.99$ \\
\hline 9 & 0.9964069756557 & 0.0035930243443 & 8.98842126 & 11108.88985 & $\mathrm{Rp}$ & $147,312.64$ \\
\hline 10 & 0.9934317047721 & 0.0065682952279 & 9.955013542 & 6076.844947 & $\mathrm{Rp}$ & $144,524.13$ \\
\hline 11 & 0.9890425154180 & 0.0109574845820 & 10.90007272 & 3642.671032 & $\mathrm{Rp}$ & $141,932.92$ \\
\hline 12 & 0.9829978001446 & 0.0170021998554 & 11.81645272 & 2347.608663 & $\mathrm{Rp}$ & $139,549.47$ \\
\hline 13 & 0.9751165135729 & 0.0248834864271 & 12.6968296 & 1604.05624 & $\mathrm{Rp}$ & $137,382.00$ \\
\hline 14 & 0.9652858528826 & 0.0347141471174 & 13.53411206 & 1149.805338 & $\mathrm{Rp}$ & $135,435.81$ \\
\hline 15 & 0.9534614113658 & 0.0465385886342 & 14.32178495 & 857.6648506 & $\mathrm{Rp}$ & $133,712.98$ \\
\hline 16 & 0.9396619345669 & 0.0603380654331 & 15.05416724 & 661.5146074 & $\mathrm{Rp}$ & $132,212.53$ \\
\hline 17 & 0.9239607321297 & 0.0760392678703 & 15.72658163 & 524.9197262 & $\mathrm{Rp}$ & $130,930.74$ \\
\hline 18 & 0.9064754488368 & 0.0935245511632 & 16.33544298 & 426.781109 & $\mathrm{Rp}$ & $129,861.60$ \\
\hline 19 & 0.8873574674085 & 0.1126425325915 & 16.87827849 & 354.3467174 & $\mathrm{Rp}$ & $128,997.31$ \\
\hline 20 & 0.8667818077430 & 0.1332181922570 & 17.35369411 & 299.6175747 & $\mathrm{Rp}$ & $128,328.77$ \\
\hline 21 & 0.8449380483198 & 0.1550619516802 & 17.76130189 & 257.4100947 & $\mathrm{Rp}$ & $127,845.94$ \\
\hline 22 & 0.8220225372211 & 0.1779774627789 & 18.10162129 & 224.2672249 & $\mathrm{Rp}$ & $127,538.30$ \\
\hline 23 & 0.7982319770506 & 0.2017680229494 & 18.37596531 & 197.8237735 & $\mathrm{Rp}$ & $127,395.05$ \\
\hline 24 & 0.7737583471418 & 0.2262416528582 & 18.5863203 & 176.42424 & $\mathrm{Rp}$ & $127,405.38$ \\
\hline
\end{tabular}




\section{Cost of Preventive Alternative}

Dilihat pada Tabel 4 bahwa untuk biaya penggantian pencegahan pada komponen sensor pada mesin AM Korin dengan metode age replacement adalah sebesar Rp.79.200.000.

Tabel 4. Cost Of Preventive Alternative

Sumber: Penulis, 2020

\begin{tabular}{c|c}
\hline \multicolumn{2}{c}{ Cost Of Preventive Alternative } \\
\hline Output Produksi & Rp. 24.000 pcs/hari \\
\hline Laba & Rp. $1.125 / \mathrm{pcs}$ \\
\hline Biaya Kehilangan Produksi (A) & Rp. 27.000 .000 \\
\hline Total Hari Kerja Tahun 2019 & 248 hari \\
\hline Age Replacement Sensor & 23 hari sekali \\
\hline Total Jumlah Penggantian Komponen (B) & 248 hari $\div 23=11$ kali \\
\hline
\end{tabular}

\begin{tabular}{|c|c|c|c|}
\hline \multicolumn{4}{|c|}{ Biaya Komponen } \\
\hline Komponen & Harga $(C)$ & Jumlah Unit (D) & $\begin{array}{c}\text { (E) Total Biaya Komponen } \\
(\mathrm{C} \times \mathrm{D})\end{array}$ \\
\hline Sensor & Rp. 600.000 & 12 & Rp. 7.200.000 \\
\hline \multicolumn{4}{|c|}{ Perhitungan Cost of preventive alternative } \\
\hline Komponen & \multicolumn{3}{|c|}{$\begin{array}{l}\text { Total Cost of preventive alternative } \\
(\mathrm{E} \times \mathrm{B})\end{array}$} \\
\hline Sensor & \multicolumn{3}{|c|}{ Rp. 79.200.000 } \\
\hline
\end{tabular}

\section{KESIMPULAN DAN SARAN}

\section{Kesimpulan}

a. Pemilihan komponen kritis menggunakan metode $A B C$ analysis dan di tampilkan dengan diagram paretto menunjukkan kelas A jatuh kepada komponen sensor dengan mewakili nilai sebesar $61.54 \%$ dari total penggunaan biaya.

b. Model Age Relacement menunjukkan selang waktu penggantian komponen yaitu 23 hari sekali, yang mengindikasikan bahwa komponen tersebut harus dilakukan penggantian sebelum rusak kembali di hari ke 23 berikutnya .

c. Tingkat efisiensi yang menjadi dampak positif pada penghematan biaya adalah sebesar Rp. 20.700 .000 atau sebesar $20.72 \%$ dari total biaya sebelumnya yaitu sebesar Rp. 99.900.000.

\section{Saran}

a. Pembaharuan setiap data kerusakan pada spreadsheet untuk menjaga keakuratan Age Replacement sehingga tidak terjadi melesetnya jadwal perawatan komponen.

b. Dibuatkan aplikasi khusus untuk model Age Replacement ini untuk memsimplifikasi atau membuat sistem menjadi userfriendly untuk digunakan oleh operator maintenance.

c. Dalam penentuan interval agar sebaiknya pada penelitian selanjutnya menggunakan penerapan internet of things sehingga kerusakan mesin dapat dipantau secara daring. 


\section{REFERENSI}

Budiyanti, V. E., Setyanto, N. W., \& Rahman, A. (2015). PERENCANAAN JADWAL PERAWATAN PREVENTIF BERBASIS KEANDALAN UNTUK MENINGKATKAN AVAILABILITY MESIN KERTAS (Studi Kasus: PT Kertas Leces (Persero). JURNAL REKAYASA DAN MANAJEMEN SISTEM INDUSTRI, 3(1), 1-10.

Fansuri, F. R., Widiasih, W., \& Nuha, H. (2017). PENENTUAN INTERVAL WAKTU PERAWATAN PREVENTIVE MAINTENANCE DAN BIAYA PERAWATAN MESIN BANDSAW DI CV . SISI JATI BENING DENGAN METODE AGE REPLACEMENT. Optimasi Sistem Industri, 1(1), 1-14.

Muhsin, A., \& Syarafi, I. (2018). ANALISIS KEHANDDALAN DAN LAJU KERUSAKAN PADA MESIN CONTINUES FRYING ( STUDI KASUS : PT XYZ ). Jurnal (OPSI) $\begin{array}{llll}\text { Optimasi Sistem } \quad \text { Industri, } & \text { 28-34. }\end{array}$ http://jurnal.upnyk.ac.id/index.php/opsi/article/viewFile/2200/1932

Praharsi, Y., Sriwana, I. K., \& Sari, D. M. (2015). Perancangan Penjadwalan Preventive Maintenance Pada PT Artha Prima Sukses Makmur. Jurnal Ilmiah Teknik Industri, 14(1), 59-65. http://journals.ums.ac.id/index.php/jiti/article/viewFile/624/364

Prawiro, Y. Y. (2017). Penentuan Interval Waktu Penggantian Komponen Kritis Pada Mesin Volpack Menggunakan Metode Age Replacement. Jurnal Teknik Industri, 16(2), 92-100. https://doi.org/10.22219/jtiumm.vol16.no2.92-100

Purnama, J., Putra, Y. A., \& Kalamollah, M. (2015). METODE AGE REPLACEMENT DIGUNAKAN UNTUK MENENTUKAN INTERVAL WAKTU PERAWATAN MESIN PADA ARMADA BUS. Seminar Nasional Sains Dan Teknologi Terapan III, 115-126.

Ramadhan, M. A. Z., \& Sukmono, T. (2018). Penentuan Interval Waktu Preventive Maintenance Pada Nail Making Machine Dengan Menggunakan Metode Reliability Centered Maintenance (RCM) II. PROZIMA (Productivity, Optimization and Manufacturing System Engineering), 2(2), 49-57. https://doi.org/10.21070/prozima.v2i2.1349

Tamara, F. (2014). Analisis Prediksi Waktu Kegagalan Transformator Menggunakan Distribusi Weibull dan Distribusi Eksponensial. Departemen Teknik Elektro, Fakultas Teknik, Universitas Indonesia, 1-19. https://library.ui.ac.id/detail?id=20402201\&lokasi=lokal

Taufik, T., \& Septyani, S. (2016). Penentuan Interval Waktu Perawatan Komponen Kritis pada Mesin Turbin Di PT Pln (Persero) Sektor Pembangkit Ombilin. Jurnal Optimasi Sistem Industri, 14(2), 238. https://doi.org/10.25077/josi.v14.n2.p238-258.2015 